\title{
PENGARUH PEMASANGAN KRIB PADA SALURAN DI TIKUNGAN 120
}

\author{
Sunaryo $^{1}$, Darwizal Daoed ${ }^{2}$, Febby Laila Sari ${ }^{3}$
}

\begin{abstract}
ABSTRAK
Sungai merupakan saluran alamiah yang berfungsi mengumpulkan curah hujan dalam suatu daerah tertentu dan mengalirkannya ke laut. Aliran sungai ini biasanya akan menyebabkan kerusakan dalam bentuk penggerusan/ erosi dan pengendapan. Kerusakan yang cukup besar dapat terjadi di sekitar tikungan sungai seperti tergerus bahkan longsornya tebing sisi luar tikungan sungai dan pengendapan di sisi dalam tikungan. Beberapa peneliti telah mengeluarkan hasil, bahwa keruntuhan tikungan dapat di atasi dengan pemasangan krib, namun belum memberikan informasi tentang jarak pemasangan dan sudut pemasangan yang efektif serta tipe krib. Untuk itu pada penelitian ini dilakukan simulasi (uji) fisik di laboratorium dengan krib, agar diperoleh pola keruntuhan tebing pada tikungan saluran dan pengaruhnya dengan pemasangan krib tidak lolos air serta variasi sudut dan jarak pemasangan krib. Perlakuan dan pengamatan dilakukan melalui variasi debit aliran terhadap keruntuhan tebing tikungan. Tebing saluran dibuat dari pasir halus setebal 10 $\mathrm{cm}$ di saluran dengan belokan $120^{\circ}$. Hasil penelitian menunjukan, bahwa pengaruh pemasangan krib dapat mengurangi volume keruntuhan dan pemasangan yang terbaik adalah dengan jarak pemasangan krib sama dengan tinggi tebing. Kemudian arah sudut pemasangan krib terbaik adalah $135^{\circ}$ ke arah hulu aliran air.
\end{abstract}

Kata Kunci : Krib, tikungan, keruntuhan tebing.

\section{PENDAHULUAN}

Sungai disamping sebagai pengendali banjir dan sumber kehidupan bagi manusia. Akan tetapi sungai juga dapat menjadi pangkal malapetaka, akibat banjir dan keruntuhan tebing serta arah aliran yang berubah. Perilaku sungai melalui debit banjir dan arah aliran sangat dominan membentuk kerusakan. Hasil pengamatan terlihat keruntuhan atau penggerusan sangat domonan terjadi di daerah tikungan. Terutama keruntuhan dinding saluran, sehingga geometrik saluran akan berubah. Perubahan geometrik saluran dapat juga akan merubah jalur sungai. Disamping itu juga akibat perilaku manusia yang melakukan penggalian atau penambangan pasir serta batu di sungai. Sebagai contoh dapat diamati pada sungai di daerah sekitar kota Padang, yaitu Batang Kuranji (Kuranji River) dan Batang Anai (Anai River). Dimana di alur sungai ini sekian kubik material dikeluarkan setiap hari berupa pasir, kerikil dan batu serta tanah timbunan. Sehubungan dengan masalah tersebut, maka pada penelitian ini dilakukan suatu percobaan laboratorium untuk mengetahui pola keruntuhan tebing pada belokan sungai dan pengaruh peletakan krib tidak lolos air sebagai pengendali keruntuhan tebing sekaligus sebagai pengendali sedimen di saluran dengan sudut tikungan $120^{\circ}$. Juga dilakukan simulasi pemsangan krib terhadap variasi debit aliran. Model dibuat di saluran $40 \times 40 \mathrm{~cm}$ dan panjang saluran $1280 \mathrm{~cm}$ dan panjang tikungan $150 \mathrm{~cm}$. Sedimen dari pasir halus yang tidak homogen dan aliran dalam kondisi jernih (clear water). Sudut dan jarak pemasangan krib divariasikan.

\footnotetext{
${ }^{1}$ Staf Pengajar Jurusan Teknik Sipil Fakultas Teknik Universitas Andalas

${ }^{2}$ Staf Pengajar Jurusan Teknik Sipil Fakultas Teknik Universitas Andalas, e-mail: darwizaldaoed@ft.unand.ac.id

${ }^{3}$ Staf Pengajar Jurusan Teknik Sipil Fakultas Teknik Universitas Andalas
} 


\section{DASAR TEORI}

\subsection{Umum}

Sungai mempunyai fungsi mengumpulkan curah hujan dalam suatu daerah tertentu dan mengalirkannya ke laut. Sungai digunakan juga untuk berbagai aspek seperti pembangkit tenaga listrik, pelayaran, pariwisata, perikanan dan bidang pertanian.

Dua proses penting dalam sungai adalah erosi dan pengendapan. Erosi terjadi pada dinding ataupun di dasar saluran. Pengendapan akan terjadi bila material yang akan dipindahkan jauh lebih berat dari pada gaya penyebab pergerakan.

\subsection{Perilaku Aliran di Tikungan}

Gaya sentrifugal pada tikungan akan menyebabkan timbulnya arus melintang sungai yang selanjutnya bersama dengan aliran utama akan membentuk aliran helicoidal. Besarnya kecepatan arus melintang ini berkisar antara 10\% - 15\% dari kecepatan arah utama aliran (Kinori, 1984 dan Legono, 1986). Dengan demikian pada sungai yang bermeander, erosi akan terjadi pada sisi luar belokan dan pengendapan terjadi pada sisi dalam belokan.

Pada daerah tikungan pengikisan terjadi diawal tikungan dan pengendapan terjadi di akhir tikungan. Dan pengikisan paling banyak di bagian luar tikungan dan pengendapan di bagian dalam tikungan (Darwizal, M. Subhi, 2006). Pengaruh kemiringan (superelevasi tikungan), memperbesar pengikisan, bila superelevasi miring ke arah dalam tikungan dan akan berkurang bila kemiringan sebaliknya. Tetapi pengerusan masih besar akibat aliran yang terpuntir (turbulensi) di tikungan (Darwizal, M. Subhi, Februarman).

\subsection{Proses Erosi pada Tebing Sungai dan Penanggulangannya}

Erosi atau penggerusan terjadi akibat adanya turbulensi tambahan yang disebabkan oleh terganggunya aliran baik besar maupun arahnya. Akibatnya terjadi material dasar atau tebing saluran yang hanyut atau bergerak terbawa oleh aliran. Untuk mengatasi erosi pada tebing dapat dilakukan dengan memakai dinding penahan berupa; bronjong, krib maupun tiang pancang.

\subsection{Pengarah Arus (Krib) atau Pelindung Tebing Tidak Langsung}

Krib merupakan suatu bentuk pelindung tebing secara tidak langsung yang digunakan untuk melindungi tebing sungai secara tidak langsung dari bahaya gerusan lokal dan gejala meander karena arus, memindahkan/mengarahkan arus sungai sesuai tujuannya dan memperdalam alur sungai dengan cara mempersempit alur, yaitu dengan memasang serial krib.

Agung Wahyono, dkk. telah melakukan penelitian mengenai kinerja pemasangan krib jenis tiang pancang pada saluran menikung $180^{\circ}$. Hasil penelitian ini menunjukkan bahwa kinerja krib telah cukup baik dalam mengarahkan distribusi aliran menuju ke tengah saluran dan relatif mampu mengurangi gerusan pada sisi tikungan.

\section{METODOLOGI}

Model dibuat pada saluran $40 \times 40 \mathrm{~cm}$ dari acrylic dan dasar saluran dari baja.Tebing saluran dibuat dari material pasir halus dengan tinggi $10 \mathrm{~cm}$ dan lebar kiria-kira setengah dari lebar saluran. Tebing di dalam tikungan dibuat sedemikian rupa mengikuti bentuk tikungan. Kemudian krib dibuat dari material yang kuat dan tidak tembus air, kecuali aliran yang kecil di pondasi krib. Selanjutnya pengamatan dilakukan terhadap perilaku keruntuhan tanpa perkuatan dan dengan perkuatan (krib). Jarak dan sudut pemasangan krib serta debit aliran divariasikan dengan beberapa kali percobaan. Bagan alir selengkapnya dapat dilihat pada Gambar 1 berikut.

\section{6 | JURNAL REKAYASA SIPIL}




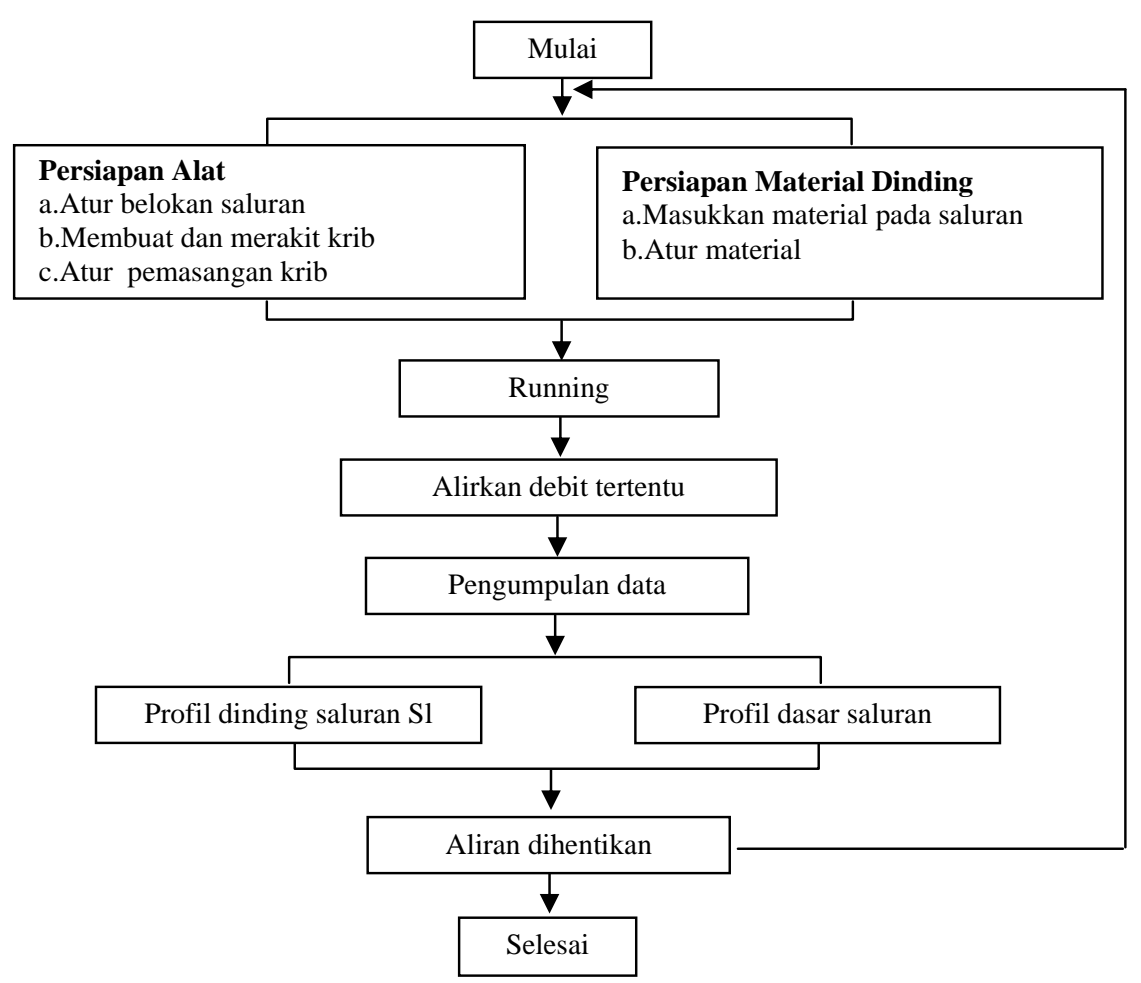

Gambar 1. Diagram Alir Pelaksanaan Penelitian

\section{PROSEDUR}

\subsection{Persiapan Penelitian}

Agar penelitian ini dapat berlangsung, maka dibutuhkan peralatan-peralatan utama yang mendukung, dimana alat-alat yang dipergunakan dalam penelitian ini diantaranya adalah sebagai berikut :

1. Saluran terbuka (open channel) dengan dimensi $40 \times 40 \mathrm{~cm}$ dengan panjang total $1280 \mathrm{~cm}$.

2. Saluran ini memiliki empat variasi belokan yaitu $60^{\circ}, 90^{\circ}, 120^{\circ}$, dan $150^{\circ}$. Penelitian ini menggunakan belokan $120^{\circ}$.

3. Krib dipasang di belokan dengan dimensi tinggi $5 \mathrm{~cm}$ dan pajang $5 \mathrm{~cm}$. Jarak pemasangan krib ini divariasikan sebagai berikut : $20 \mathrm{~cm}, 10 \mathrm{~cm}$, dan variasi $20 \mathrm{~cm}$ dan $10 \mathrm{~cm}$ dengan sudut pemasangan krib ini divariasikan menjadi sudut $45^{\circ}, 90^{\circ}$ dan $135^{\circ}$.

4 Dinding tebing dibuat tegak lurus dengan lebar $20 \mathrm{~cm}$ (setengah lebar saluran), setebal $10 \mathrm{~cm}$. Material dinding sedimen yang digunakan dalam penelitian ini merupakan sedimen yang telah ditentukan gradasi butirannya berdasarkan proses Analisa Saringan (Sieve Analysis), yaitu material yang tertahan saringan $20(0,84 \mathrm{~mm})$ dan $100(0,15 \mathrm{~mm}) . ।$

\subsection{Prosedur Penelitian}

Prosedur penelitian yang dilakukan adalah sebagai berikut :

1. Pemasangan krib dengan tinggi $5 \mathrm{~cm}$ dan panjang $5 \mathrm{~cm}$. Sudut dan jarak pemasangan krib divariasikan.

2. Alirkan air dengan menghidupkan pompa dari sumber dengan debit tertentu. Setelah aliran sampai pada kondisi aliran seragam atau kondisi stabil sudah dicapai, maka dapat dimulai 
proses pengamatan selanjutnya. Penyusunan krib sperti gambar - 2 Sketsa pemasangan krib dan arah aliran dan gambar -3 Potongan melintang saluran.
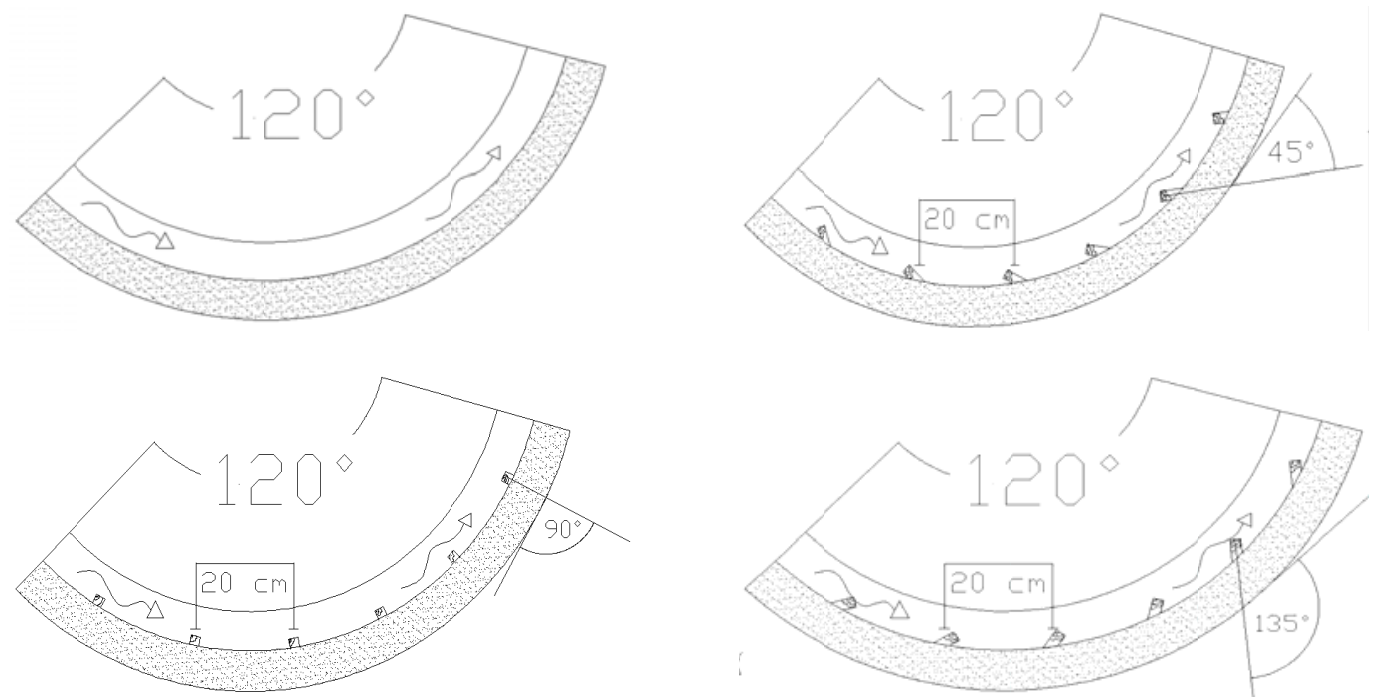

Gambar 2. Sketsa Arah Pemasangan Krib

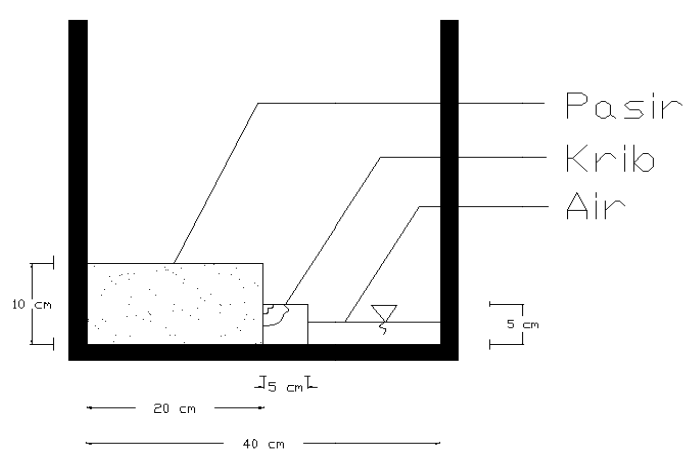

Gambar 3. Potongan Melintang Saluran

3. Amati awal keruntuhan sedimen.

4. Apabila sudah tidak terjadi lagi pergerakan partikel sedimen, lakukan pengambilan data keruntuhan dinding pada tiap-tiap segmen.

5. Catat profil aliran.

6. Ulangi prosedur no.2 - no.9 untuk tiap variasi debit yang direncanakan.

7. Setiap perlakuan debit aliran di ukur dengan alat ukur.

8. Keruntuhan diukur kedalamannya dari kondisi awal dan lebarnya. Sebelumnya sudah di buatkan grid untuk membantu dalam menghitung luas dan volume runtuh.

\section{HASIL PENELITIAN}

Data hasil pengamatan selanjutnya dijadikan sebagai input data pada software Autocad Land Development untuk pembuatan kontur keruntuhan dindingnya. Berikut gambar hasil simulasi dan pola keruntuhan pada setaip debit aliran. Debit aliran diatur dari kecil hingga besar sebagai berikut. 

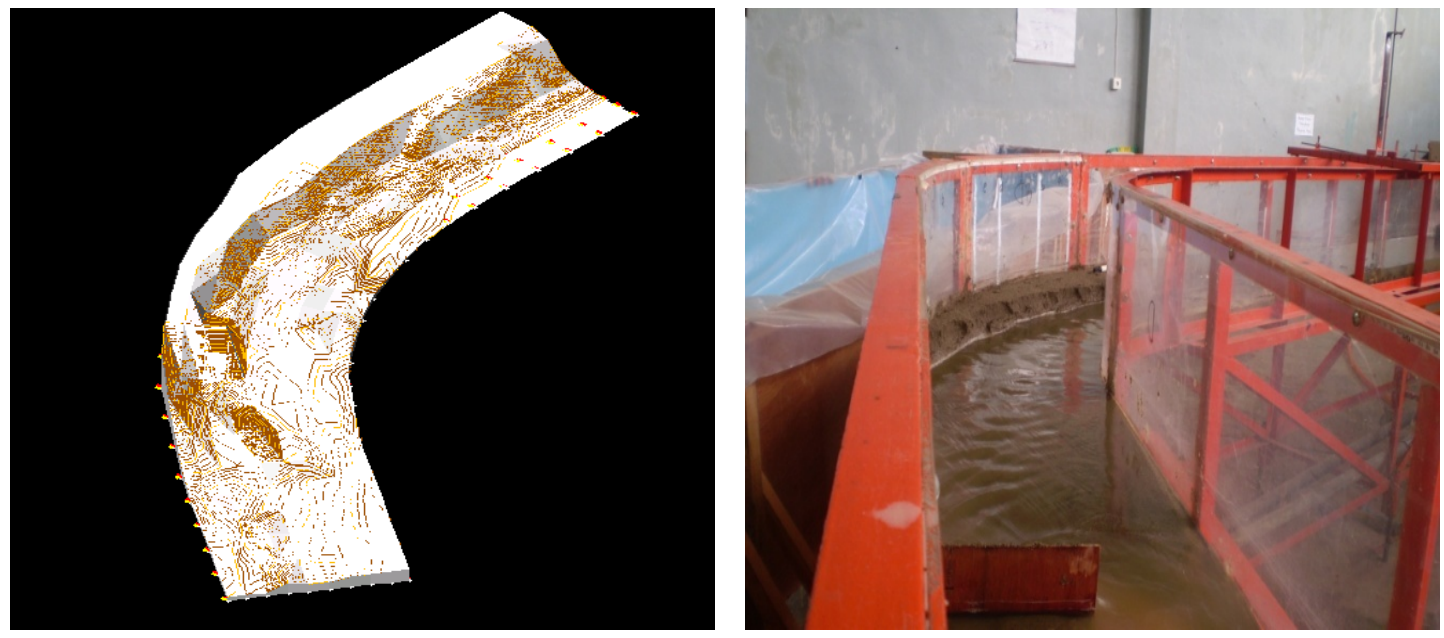

Gambar 4. Kontur Pengamatan pada Belokan $120^{\circ}$ Tanpa Krib dan Debit 2,10 lt/s
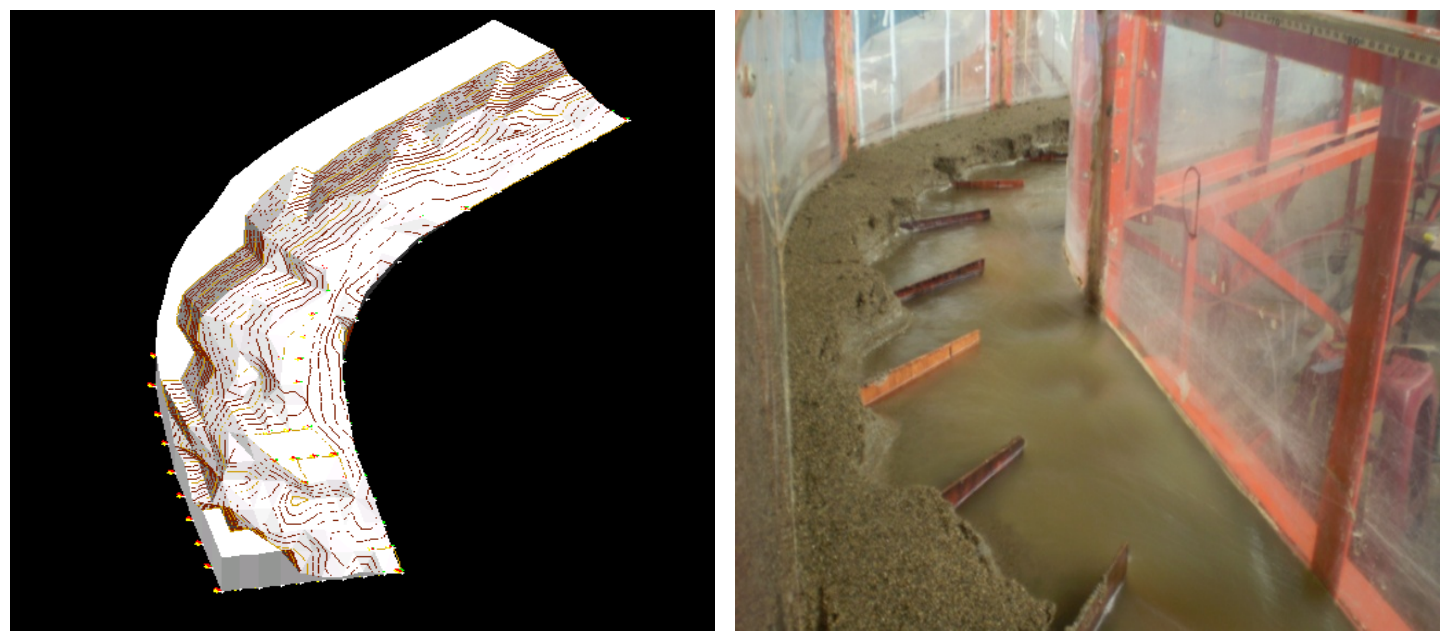

Gambar 5. Kontur Pengamatan pada Belokan $120^{\circ}$ dengan Krib sudut $45^{\circ}$ dan Debit 1,96 lt/s
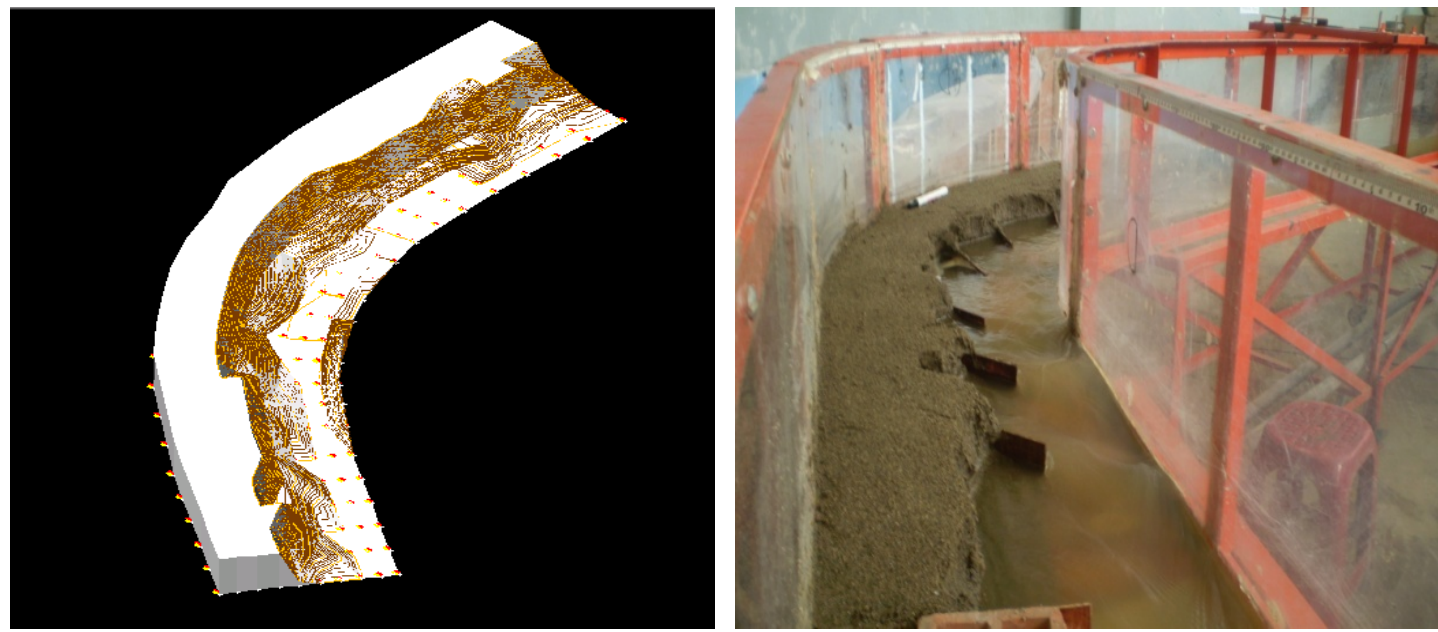

Gambar 6. Kontur Pengamatan pada Belokan $120^{\circ}$ dengan Krib sudut $135^{\circ}$ dan Debit 2,05 lt/s 

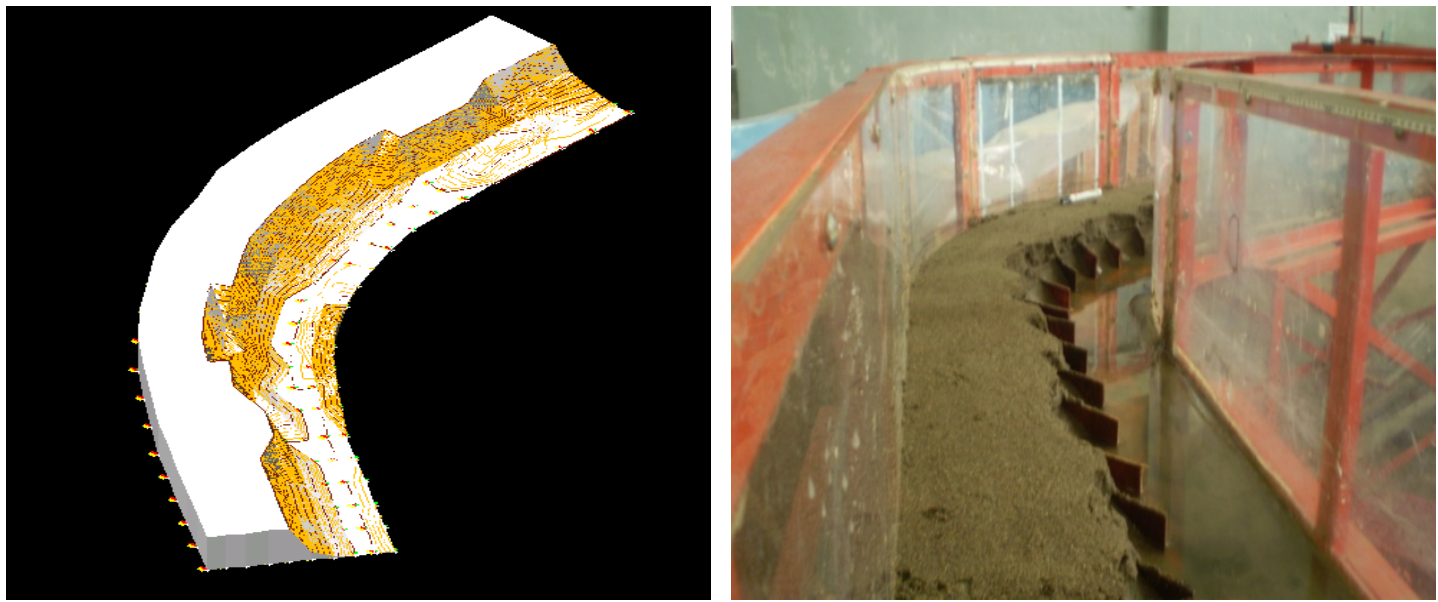

Gambar 7. Kontur Pengamatan pada Belokan $120^{\circ}$ dengan Jarak Pemasangan antar Krib $10 \mathrm{~cm}$ Sudut $135^{\circ}$ dan Debit 2,27 lt/s
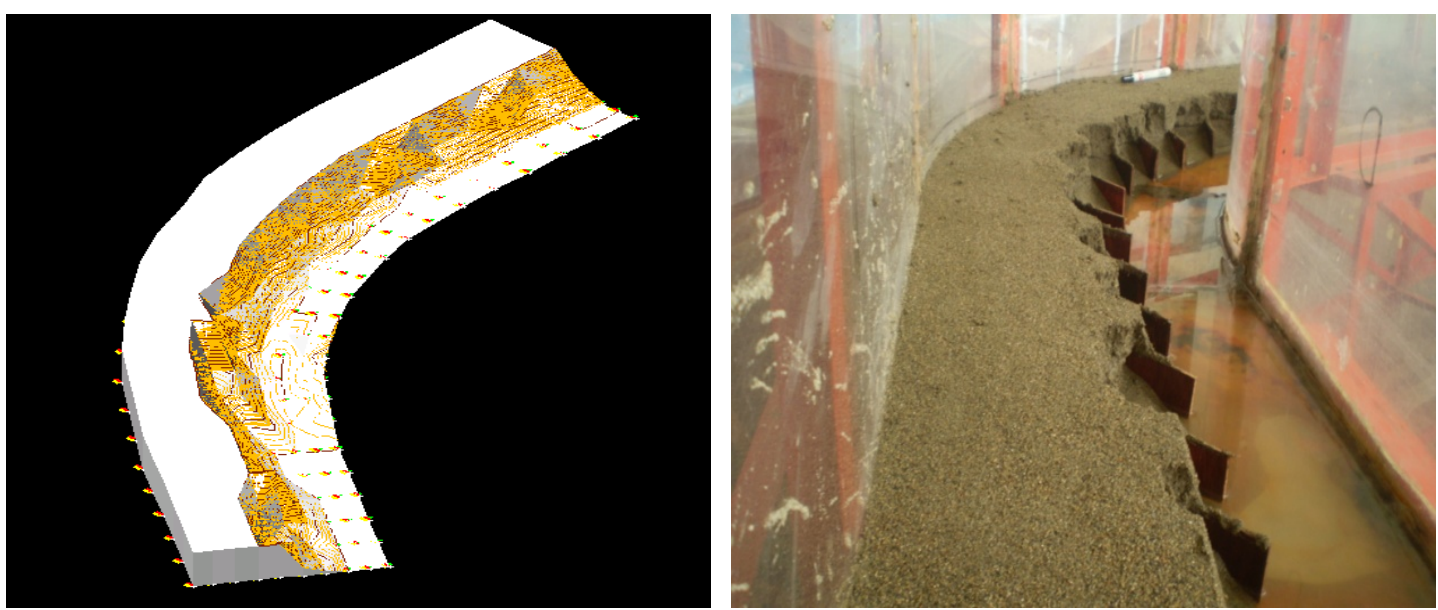

Gambar 8. Kontur Pengamatan pada Belokan $120^{\circ}$ dengan Jarak Pemasangan antar Krib $10 \mathrm{~cm}$ Sudut $135^{\circ}$ dan Debit 2,19 lt/s
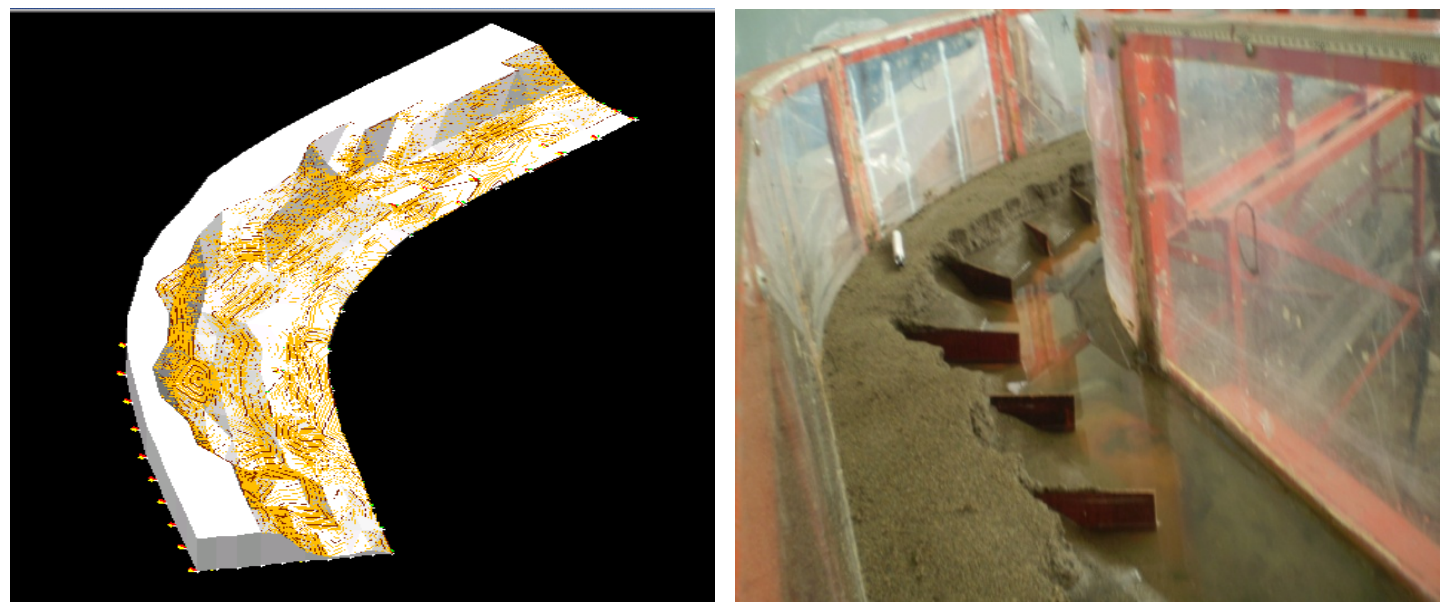

Gambar 9. Kontur Pengamatan pada Belokan $120^{\circ}$ dengan Jarak Pemasangan antar Krib 20 cm Sudut $135^{\circ}$ dan Debit 1,72 lt/s 

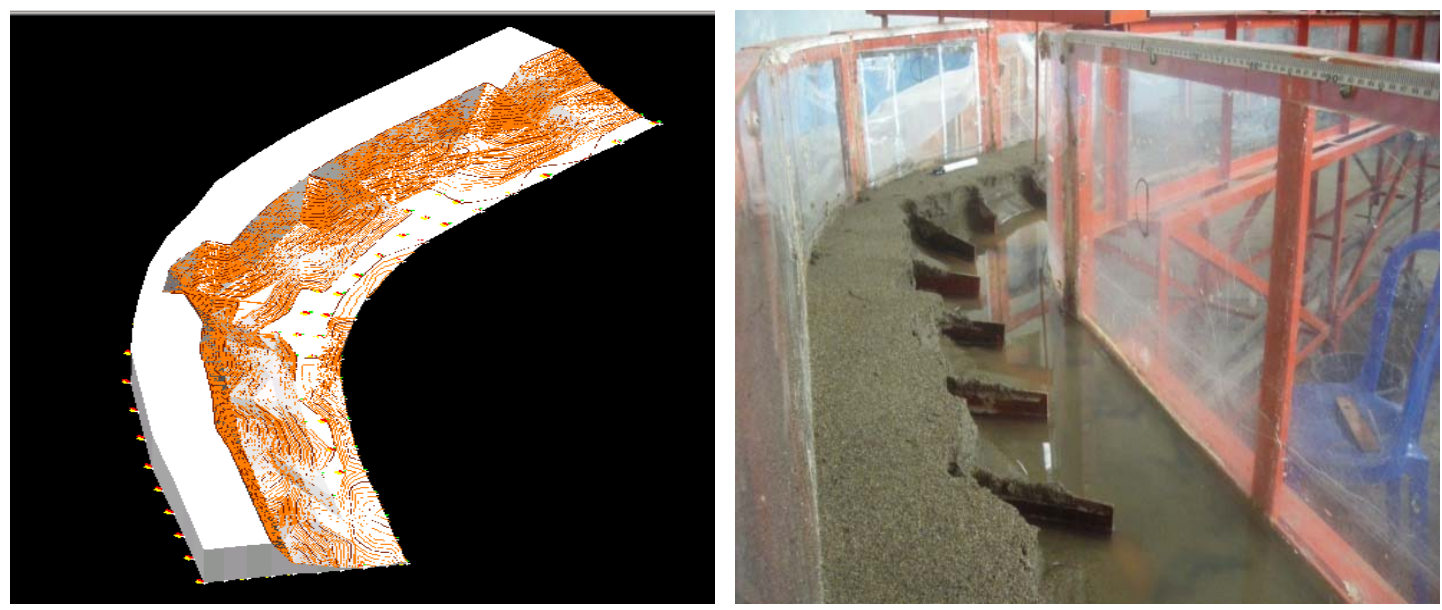

Gambar 10. Kontur Pengamatan pada Belokan $120^{\circ}$ dengan Jarak Pemasangan antar Krib $20 \mathrm{~cm}$ Sudut $135^{\circ}$ dan Debit 2,02 lt/s
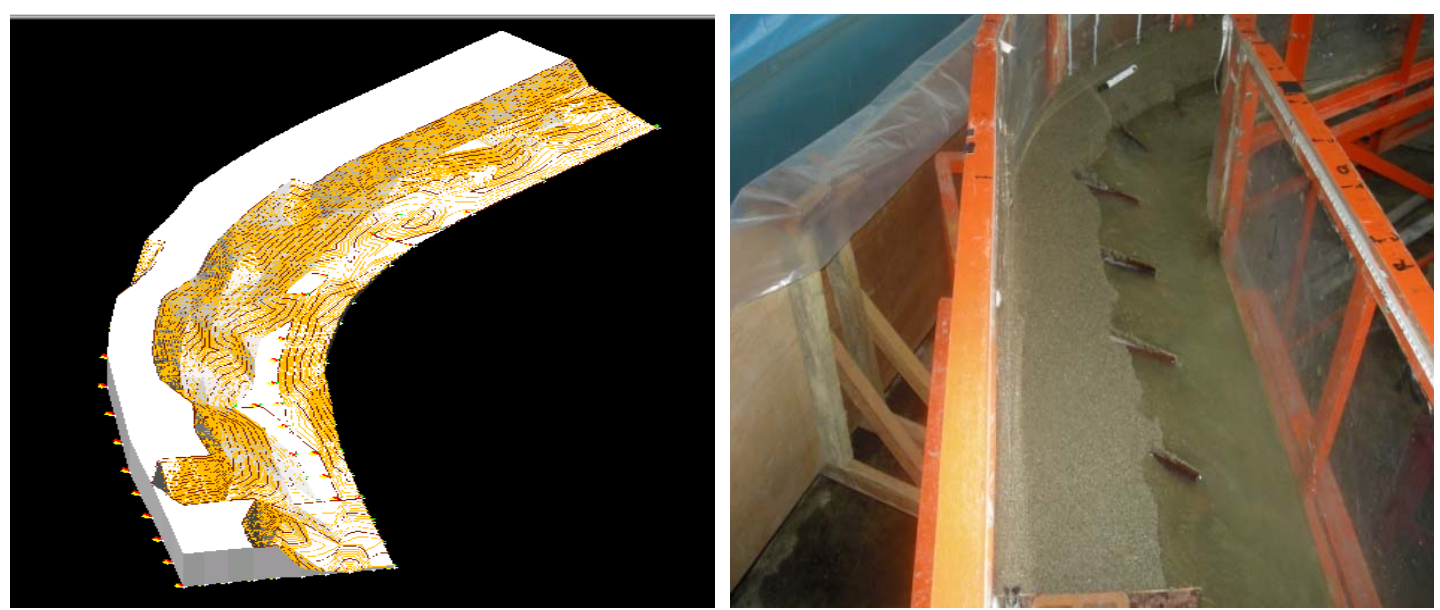

Gambar 11. Kontur Pengamatan pada Belokan $120^{\circ}$ dengan Jarak Pemasangan antar Krib $20 \mathrm{~cm}$ Sudut $135^{\circ}$ dan Debit 2,17 lt/s
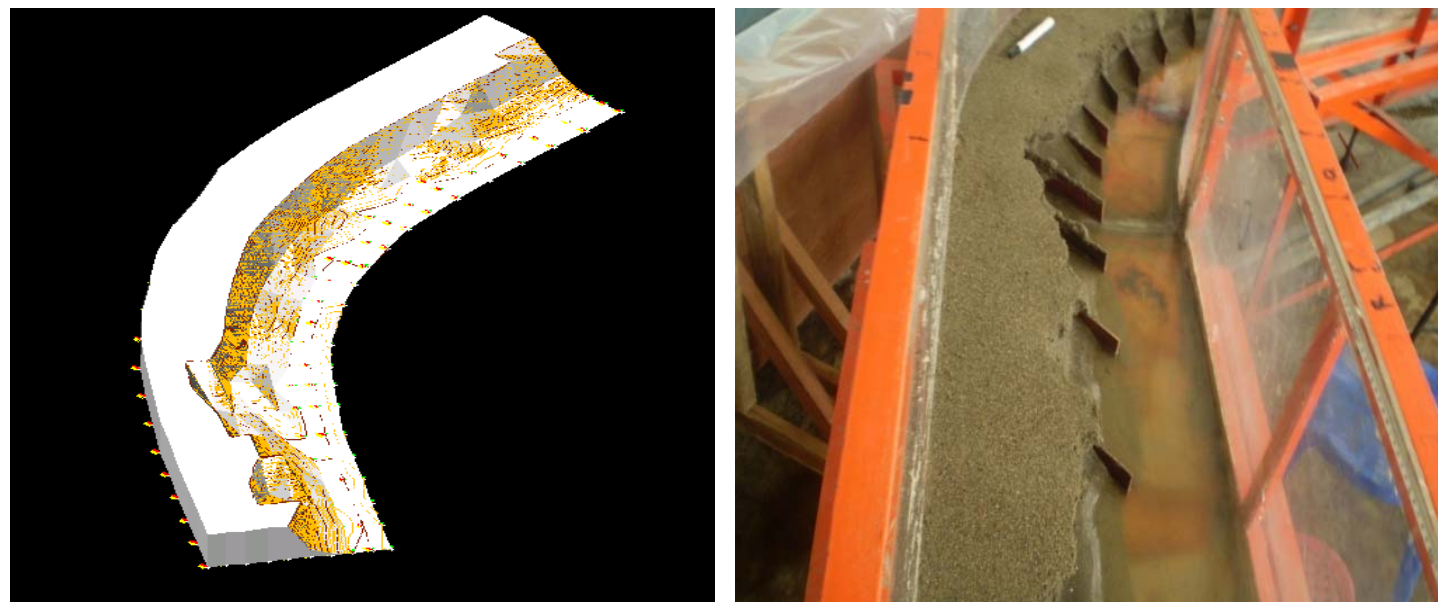

Gambar 12. Kontur Pengamatan pada Belokan $120^{\circ}$ dengan Jarak Pemasangan antar Krib variasi $10 \mathrm{~cm}$ dan $20 \mathrm{~cm}$, , Sudut $135^{\circ}$ dan Debit 2,27 lt/s 

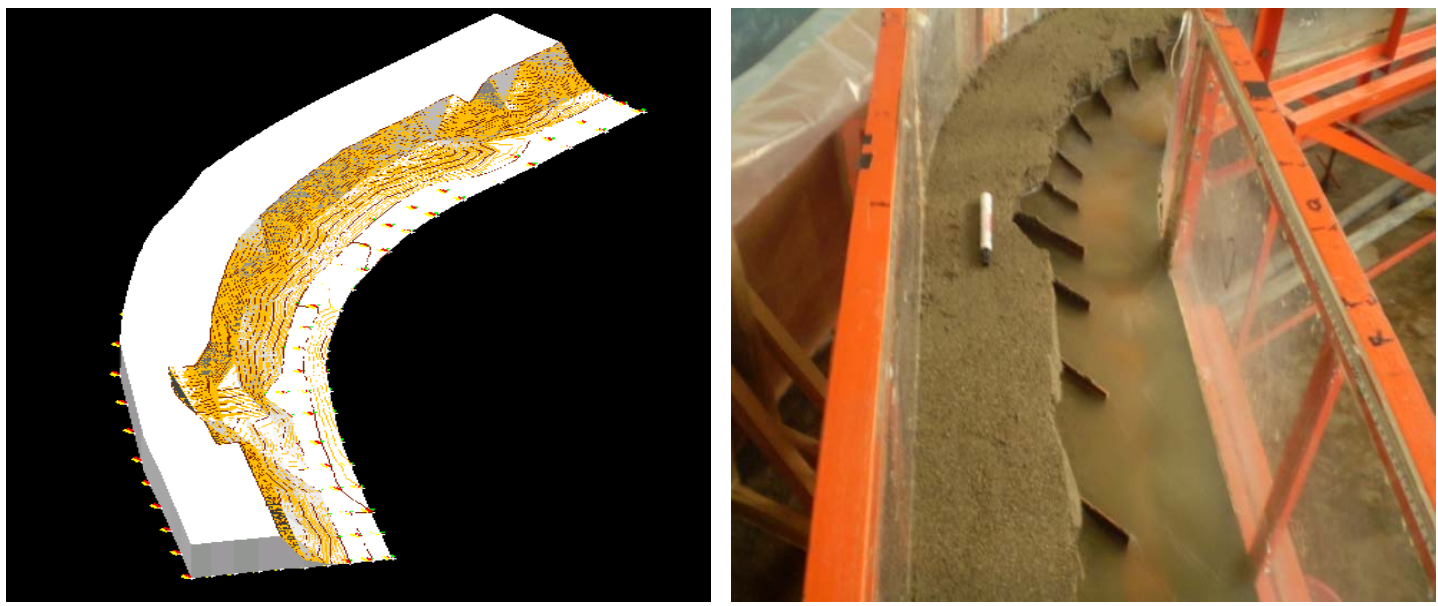

Gambar 13. Kontur Pengamatan pada Belokan $120^{\circ}$ dengan Jarak Pemasangan antar Krib variasi $10 \mathrm{~cm}$ dan $20 \mathrm{~cm}$, Sudut $135^{\circ}$ debit $2,15 \mathrm{lt} / \mathrm{s}$

\section{ANALISIS PENGARUH PEMASANGAN KRIB}

\subsection{Variasi Arah Sudut Pemasangan Krib ke Arah Hulu Aliran terhadap Volume Keruntuhan Dinding}

Setelah dilakukan pengamatan, pengukuran dan perhitungan terlihat, bahwa keruntuhan dinding semakin besar dengan meningkatnya debit aliran serta sudut krib semakin besar, seperti grafik berikut.

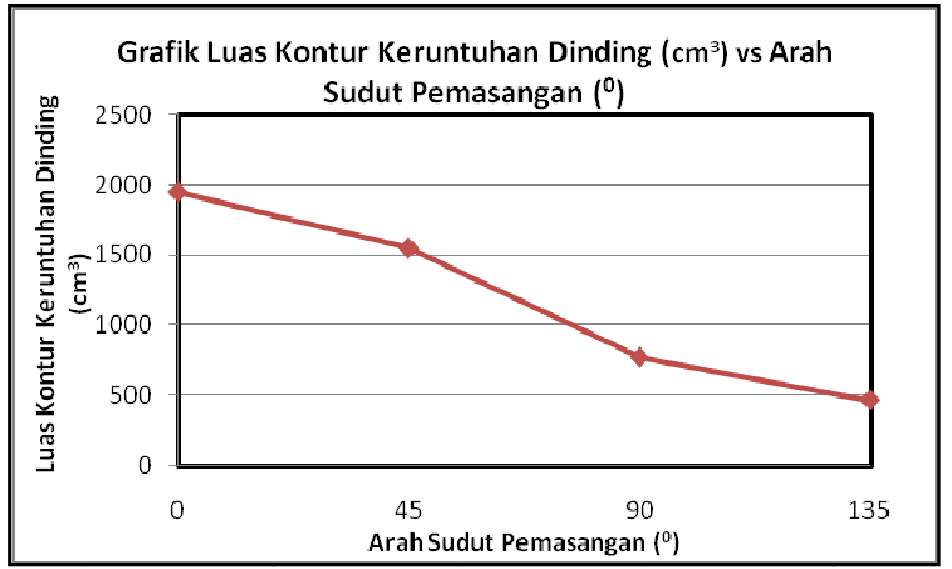

Gambar 14. Grafik Perbandingan Luas Kontur Keruntuhan (cm) vs Arah Sudut Pemasangan Krib $\left({ }^{\circ}\right)$

\subsection{Variasi Jarak Pemasangan Krib, Debit Aliran Terhadap Volume Keruntuhan Dinding}

Pada grafik berikut dibuatkan hubungan antara debit aliran dengan volume keruntuhan yang terjadi. Dimana secara umum cendrung menaik keruntuhannya terhadap pertambahan debit aliran dengan kondisi krib dengan sudut pemasangan $135^{\circ}$. 


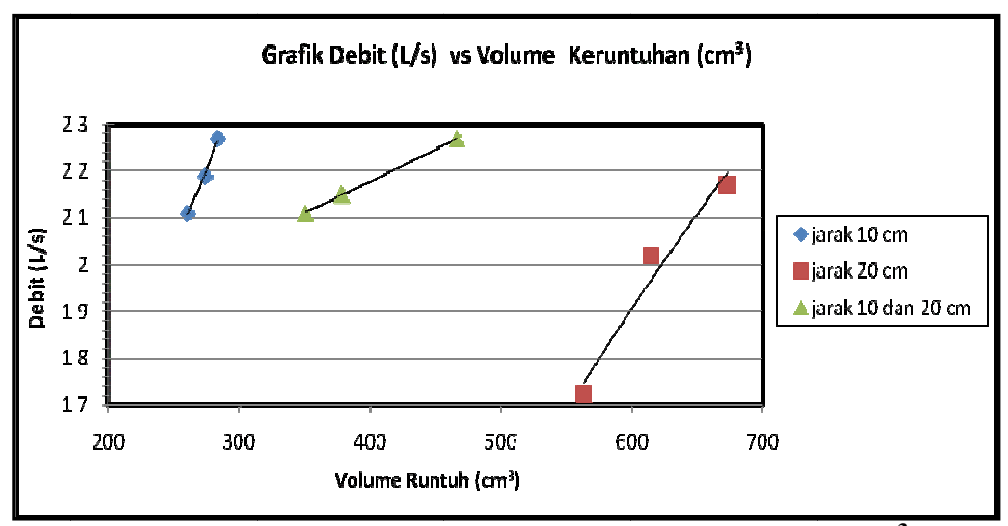

Gambar 15. Gabungan Grafik Perbandingan Volume Keruntuhan $\left(\mathrm{cm}^{3}\right)$ vs Debit (lt/s) pada Jarak Pemasangan Krib 10, 20, variasi 10 dan $20 \mathrm{~cm}$ Serta Sudut $135^{\circ}$

\section{PEMBAHASAN}

Pada Gambar 14 terlihat bahwa semakin besar sudut pemsangan krib, maka luas bidang keruntuhan akan semakin kecil. Luas bidang keruntuhan paling kecil terjadi pada arah sudut pemasangan krib ke arah hulu aliran adalah $135^{\circ}$. Hal ini terlihat pada saat simulasi, dimana turbulensi air semakin kecil. Artinya arus semakin diarahkan, sehingga penggerusan di dasar saluran semakin kecil. Selanjutnya gambar-15 terlihat pengaruh variasi jarak pemasangan krib dan debit aliran terhadap volume keruntuhan dinding, dimana dengan memvariasikan jarak pemasangan krib dan debit aliran didapatkan volume keruntuhan yang bervariasi. Volume keruntuhan cenderung mengecil pada jarak pemasangan krib dirapatkan $(10 \mathrm{~cm})$ dan debit yang kecil. Hal ini terjadi karena turbulensi air semakin kecil (ruang berputarnya yang sempit), sehingga tebing cukup stabil. Sebaliknya dengan jarak antar krib diperlebar akan memperbesar luas keruntuhan, terlihat dinding semakin tidak stabil.Begitu juga dengan memperbesar debit aliran, dimana keruntuhan semakin cepat dan semakin besar luas bidang runtuh. Sebagai kontrol, bila jarak pemasangan krib divariasikan dari $10 \mathrm{~cm}$ dan $20 \mathrm{~cm}$, diperoleh volume keruntuhan antara jarak pemasangan $10 \mathrm{~cm}$ dan $20 \mathrm{~cm}$ ketika variasi masing-masingnya.

\section{KESIMPULAN DAN SARAN}

Dari pengolahan terhadap data dan pengamatan hasil percobaan dapat disimpulkan bahwa :

1. Pemasangan bangunan krib pada tikungan dapat mengurangi erosi dinding secara signifikan, sehingga trase saluran relatif tidak mengalami perubahan.

2. Kecenderungan arah pemasangan krib yang paling baik untuk mengurangi keruntuhan dinding dan pengendapan sedimen pada belokan saluran adalah sudut $135^{\circ}$ ke arah hulu saluran.

3. Kecenderungan jarak pemasangan krib yang paling baik untuk mengurangi keruntuhan dinding dan pengendapan sedimen adalah sama tinggi dengan tebing (talud).

4. Semakin kecil debit aliran maka semakin kecil pula volume keruntuhan yang terjadi.

5. Penelitian ini dapat diamati lebih lanjut, bila tebing saluran bagian dalam tikungan juga dibuat dari material yang sama dengan di luar tikungan dan dasar saluran juga tergerus.

\section{DAFTAR PUSTAKA}

Balai Sungai Pusat Litbang Sumber Daya Air, Pengamanan Sungai, Badan Litbang Pekerjaan Umum Bandung. 
Daoed, Darwizal; M. Subhi NH; Junaidi, (2006), Pengaruh Variasi Geometri Tikungan Terhadap Karakteristik Penyebaran Sedimen dan Pembentukan Lapisan Armouring di Dasar Saluran, Laporan Hasil Penelitian Fundamental, Dikti, Dep. Diknas.

Daoed, Darwizal, Februarman, M. Subhi NH., (2009), Pengaruh Bentuk dan Superelevasi Tikungan Terhadap Pola Penyebaran Sedimen, Laporan Hasil Penelitian Fundamental, Dikti Dep. Diknas.

Februarman, (2009), Pengaruh Pemasangan Ground Sill terhadap Gerusan Sisi Belokan Luar dan Pola Sedimentasi di Tikungan Sungai, Jurnal Teknika, Padang.

Wiyono, Agung, (2002), Penelitian dengan Model Fisik Pemasangan Krib pada Saluran Menikung $180^{\circ}$ dengan Ketebalan Material $8 \mathrm{~cm}$ dan 20 cm, Jurnal Itenas No 1 Vol 6 Maret-Mei 2002, Bandung. 